\title{
CANCER
}

\section{Adenoma prevalence and cancer risk in familial non-polyposis colorectal cancer}

\author{
G Lindgren, A Liliegren, E Jaramillo, C Rubio, A Lindblom
}

Gut 2002;50:228-234

Background and aims: Polypectomy in the colon has been shown to prevent colorectal cancer in both the general population and in familial colorectal cancer. Individuals with a family history of colorectal cancer have an increased risk of the disease. Over a period of 10 years, 304 subjects at risk were included in ongoing surveillance with regular colonoscopies. To compile the medical findings and experience generated during this period, a retrospective cross sectional study was performed.

Subjects: Subjects were classified into three family groups: families with hereditary non-polyposis colorectal cancer (HNPCC); families with hereditary colorectal cancer (HCC, non-Lynch syndrome); and a third group of families with only empirical risk estimates based on a family history of two close relatives (TCR) with colorectal cancer.

Methods: The risk population was studied with regard to age at onset, prevalence, number, cancer risk, size, dysplasia, and distribution of adenomas. A comparison was made within the family groups and with a reference group representing the general population.

See end of article for authors' affiliations

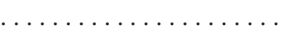

Correspondence to: A Lindblom, Department of Clinical Genetics, CMM L8-02, S 17176

Stockholm, Sweden: annika.lindblom@cmm.ki.se

Accepted for publication 23 April 2001
Results: In total, 195 adenomas and six cancers were detected among 85 individuals. The relative risk of having an adenoma in the whole risk population compared with the general population was 2.6. Subjects from TCR families had most adenomas and HNPCC subjects had the least. A shift from proximal adenomas to distal carcinomas in families with HCC and TCR suggested a higher cancer risk in distal adenomas in these syndromes. HNPCC families showed a younger age at onset and adenomas with a higher degree of dysplasia. In HNPCC, there was a similar localisation of adenomas and carcinomas, suggesting a high risk of cancer in all adenomas.

Conclusions: There was clear overrepresentation of adenomas in all three family types compared with the reference population. In HNPCC, we found earlier onset of adenomas and faster progression to cancer. Families with HCC, and even more so TCR subjects, had a later onset and lower risk of cancer from proximal adenomas. Based on these results, surveillance protocols in Sweden have been revised.
$\mathrm{T}$ he lifetime risk of developing colorectal cancer is $5 \%$, with an increased risk for individuals who have close relatives with colorectal cancer, especially if diagnosed at an early age. ${ }^{1}$ Depending on the family history and presence of an inherited mutation to colorectal cancer, the risk variability for colorectal cancer is up to $70 \%$. Screening programmes, including colonoscopies in families with familial colorectal cancer as well as in the general population, reduce the incidence of colorectal cancer and seem to prevent mortality from colon cancer. ${ }^{2-4}$ Since 1990, families at risk have been counselled and invited to join a surveillance programme at the Karolinska Hospital with regular colonoscopy, and subjects with an increased risk of colorectal cancer of more than $10 \%$ have been offered regular colonoscopy every two years. The surveillance programme included the following types of risk syndromes: hereditary non-polyposis colorectal cancer (HNPCC); hereditary colorectal cancer (HCC); and individuals without a clear pattern of inheritance but with a family history of the disease. Patients with familial adenomatous polyposis were not included as they are usually treated with total colectomy.

HNPCC is an autosomal dominant syndrome predisposing to the development of colorectal cancer. ${ }^{5}$ It is caused by germline mutations in the DNA mismatch repair genes MSH2, MLH1, PMS1, PMS2, and MSH6. ${ }^{5}$ The syndrome is characterised by high penetrance, early onset, a more favourable prognosis than sporadic colorectal cancer, and right sided tumours. ${ }^{5}$ Tumours generally show microsatellite instability (MSI). ${ }^{67}$ The syndrome is also associated with a broad spectrum of extracolonic cancers, primarily in the endometrium, urinary tract, and small intestine. ${ }^{8}$ As the genes were cloned, more than 300 germline mutations in DNA mismatch repair genes were identified (ICG-HNPCC database). ${ }^{\text {? }}$

Families not fulfilling the Amsterdam criteria for HNPCC $^{10}$ because of older age at onset but with a family history of three or more first degree relatives with colorectal cancer are likely to segregate unknown predisposing gene mutations, causing HCC, and they have a risk similar to families with Lynch syndrome. ${ }^{11}$ Apart from HNPCC and HCC, some individuals have an empiric increased risk of colorectal cancer because of a family history. Individuals with one first and one second degree or two first degree relatives (here termed two close relatives (TCR)) affected by colorectal cancer have a risk estimation of $10-20 \%$ based on empirical data. ${ }^{11}$ Finally, individuals with colorectal cancer at a very early age are likely to have a predisposition for the disease, and their children have an empiric increased cancer risk. ${ }^{11}$

A retrospective cross sectional study was performed to evaluate the surveillance programme in all subjects who had undergone regular colonoscopies for $1-10$ years. An attempt was made to compare the prevalence, number, localisation, cancer risk, size, degree of dysplasia, and age at onset of adenomas between the risk groups and the general population. Sex differences were also studied.

Abbreviations: HNPCC, hereditary non-polyposis colorectal cancer; $\mathrm{HCC}$, hereditary colorectal cancer; TCR, two close relatives with colorectal cancer; OCR, one close relative with colorectal cancer; MSI, microsatellite instability; $R R$, relative risk. 
Table 1 Families included in the study

\begin{tabular}{lrlr}
\hline Family type & Criteria & No of families \\
\hline HNPCC & 1 & Germline mutation in hMSH2, hMLH1, or hMSH6 \\
& 2 & Amsterdam HNPCC+MSI pos+negative mutation screen & 25 \\
HCC & 3 & Amsterdam HNPCC+MSI nd+mutation screen nd & 13 \\
& 1 & Non-Amsterdam hereditary CRC+MSI neg+negative mutation screen & 18 \\
TCR & 2 & Amsterdam HNPCC+MSI neg+negative mutation screen & 2 \\
& 3 & Non-Amsterdam hereditary CRC+MSI nd+mutation screen nd & 5 \\
& 1 & Two close relatives+MSI neg+negative mutation screen & 5 \\
OCR & 2 & Two close relatives+MSI nd+negative mutation screen & 5 \\
Total no families & 1 & Two close relatives+MSI nd+mutation screen nd & 29 \\
\hline \multirow{2}{*}{ HNPCC, hereditary non-polyposis colorectal cancer; HCC, hereditary colorectal cancer; TCR, two close } \\
relatives with colorectal cancer; OCR, one close relative with colorectal cancer; CRC, colorectal cancer; MSI, \\
microsatellite instability; nd, not done.
\end{tabular}

\section{MATERIALS AND METHODS \\ Subjects}

Subjects included in this study were from the Cancer Family Clinic at Karolinska Hospital from 1990 to 1999. A medical history was given by the index patient and all diagnoses in the family were confirmed by medical records, pathological reports, or in very few cases death certificates. The general screening interval was every two years. After polypectomy of at least one adenoma, a new colonoscopy was performed the following year. Data from the colonoscopies were recorded anonymously in Stat View 5.0.1. Families were classified according to family type (HNPCC, HCC, or TCR), or one close relative (OCR) using information available from clinical records (table 1). The information used for classifying families included family history and, if available, data on MSI tests in tumours and mutation screening in mismatch repair genes in affected members. All individuals were divided into risk groups as follows. Tested carriers in HNPCC families (risk group 1) were considered to have a $70 \%$ lifetime risk. ${ }^{12}$ According to the rules applied to mendelian inheritance, untested first generation members at risk in a HNPCC family have a $35 \%$ lifetime risk (risk group 2). Their children who sometimes were under surveillance have a $17 \%$ lifetime risk (risk group 3). Subjects in HNPCC families who were under surveillance before testing but tested negative for mutation at the time of the study (risk group 4) were assumed to have the same risk (5\%) as the normal population. Obvious gene carriers in families with HCC (risk group 5) have empiric risk values similar to HNPCC families $(70 \%) .{ }^{11}{ }^{13}$ First generation (risk group 6) family members accordingly have a lifetime risk of $35 \%$ and the second generation (risk group 7) at risk in these families has an estimated lifetime risk of $17 \%$. TCR subjects with a family history of colorectal cancer (risk group 8) have an empirical risk of $10-20 \% .{ }^{1113}$ OCR subjects with one relative with early age of onset (risk group 9) have a lifetime empiric risk of $20-40 \%{ }^{1}{ }^{11} 13$

A reference group based on three published forensic autopsy studies was used for estimates of adenoma prevalence in the normal population. ${ }^{14-16}$ In reference group 1, 185 men and 118 women underwent forensic autopsy. Colonic biopsies were examined for prevalence, size, and degree of dysplasia of identified adenomas. ${ }^{14}$ Reference group 2 consisted of 198 men and 167 women who underwent autopsy/forensic autopsy. The study included prevalence, type, and location of adenomas. ${ }^{15}$ Reference group 3 comprised autopsies in 370 women and 310 men from areas with various incidences of colorectal cancer. Prevalence of adenomas, size, degree of dysplasia, and site of the adenomas were reported..$^{16}$ In a comparison of prevalence in the study group versus the reference population, only individuals less than 54 years of age were included in the analysis. The reason was an uneven distribution of subjects in different age cohorts; in the reference group $75 \%$ of the cohort were older than 54 years while only 33\% were over 54 years in the study group. Also, it was considered relevant to study the prevalence of adenomas at an early age as this is typical of a predisposition to cancer. Thus in the comparison between the study group and the general population, 338 subjects from the reference group and 204 from the study group were used.

\section{Statistical methods}

Differences in prevalence of adenomas between the three family types and the reference population were calculated as relative risks (RR). Differences between the family types were tested by $\chi^{2}$ test. Logistic regression was used to test the influence of sex with respect to the risk of developing an adenoma. The number of adenomas among individual subjects with adenomas were compared using the hazard ratio. Age at first adenoma was analysed by ANOVA with two independent factors, sex and family type. The Tukey post hoc test was then used for pairwise comparisons of family types and age at onset of adenomas. Differences between the family types regarding size and degree of dysplasia were compared using the $\chi^{2}$ test. Differences in localisation of adenomas and carcinomas in the bowel were analysed using $\chi^{2}$ statistics, and corresponding $95 \%$ confidence intervals for differences in proportions were calculated.

\section{Genetic testing}

MSI tests and genetic testing were performed either as part of previous studies or as part of clinical handling and counselling after 1997, and were not part of this study. The MSI test used established methods and criteria. ${ }^{17}{ }^{18}$ Methods used for mutation screening were denaturant gradient gel electrophoresis, protein truncation test, Southern blot, and direct sequencing. ${ }^{19}$

\section{RESULTS}

In total, 304 subjects underwent 765 colonoscopies (table 2). Ten colorectal cancers were found in nine individuals before recruitment into the surveillance programme. These tumours have been included in table 2 to obtain correct values for prevalence and mean age at onset of adenomas or cancer in the different family types. History of previous adenomas was unknown, and most individuals had their first colonoscopy through this programme. Four individuals had colorectal cancer detected at their first colonoscopy, and two individuals developed a metachronous colorectal cancer during surveillance.

\section{Prevalence and number of adenomas}

The RR value of developing an adenoma before the age of 54 years in all risk groups (except tested non-carriers) was 2.6 compared with the general population $(p=0.001)$ (table 3$)$. Sex had no influence on these results. RR was even higher 
Table 2 Follow up of regular colonoscopies as prevention in individuals with an increased risk of colorectal cancer

\begin{tabular}{|c|c|c|c|c|c|c|c|c|c|c|}
\hline \multirow[b]{2}{*}{ Risk group } & \multicolumn{4}{|l|}{ HNPCC } & \multicolumn{3}{|l|}{$\mathrm{HCC}$} & \multicolumn{2}{|c|}{ Family history } & \multirow[b]{2}{*}{ Total } \\
\hline & 1 & 2 & 3 & 4 & 5 & 6 & 7 & 8 (TCR) & 9 (OCR) & \\
\hline Estimated risk of cancer ( $\%)$ & 70 & 35 & 17 & 5 & 70 & 35 & 17 & 15 & 30 & \\
\hline No colonscopies & 151 & 119 & 15 & 50 & 10 & 220 & 52 & 133 & 15 & 765 \\
\hline No patients $(M / F)$ & $\begin{array}{l}45 \\
(20 / 25)\end{array}$ & $\begin{array}{l}48 \\
(27 / 21)\end{array}$ & $5(0 / 5)$ & $\begin{array}{l}23 \\
(12 / 11)\end{array}$ & $4(1 / 3)$ & $\begin{array}{l}83 \\
(33 / 50)\end{array}$ & $\begin{array}{l}23 \\
(11 / 12)\end{array}$ & $\begin{array}{l}64 \\
(16 / 48)\end{array}$ & $\begin{array}{l}9 \\
(3 / 6)\end{array}$ & $\begin{array}{l}304 \\
(123 / 181)\end{array}$ \\
\hline Mean age $(y)(M / F)$ & $\begin{array}{l}45.7 \\
(46 / 45)\end{array}$ & $\begin{array}{l}42.9 \\
(40 / 47)\end{array}$ & $\begin{array}{l}25 \\
(0 / 25)\end{array}$ & $\begin{array}{l}40.7 \\
(41 / 41)\end{array}$ & $\begin{array}{l}70.5 \\
(72 / 70)\end{array}$ & $\begin{array}{l}49.5 \\
(49 / 50)\end{array}$ & $\begin{array}{l}41.8 \\
(45 / 39)\end{array}$ & $\begin{array}{l}50 \\
(42 / 53)\end{array}$ & $\begin{array}{l}37.9 \\
(38 / 38)\end{array}$ & $\begin{array}{l}46.3 \\
(45 / 48)\end{array}$ \\
\hline Total No adenomas & 26 & 13 & 0 & 3 & 5 & 61 & 6 & 81 & 0 & 195 \\
\hline Total No carcinomas & 15 & 0 & 0 & 0 & 1 & 0 & 0 & 0 & 0 & 16 \\
\hline Subjects with adenomas or carcinomas & 22 & 9 & 0 & 3 & 2 & 24 & 4 & 21 & 0 & 85 \\
\hline Prevalence (\%) (M/F) & $\begin{array}{l}49 \\
(55 / 44)\end{array}$ & $\begin{array}{l}19 \\
(26 / 10)\end{array}$ & 0 & $\begin{array}{l}13 \\
(25 / 0)\end{array}$ & $\begin{array}{l}50 \\
(100 / 33)\end{array}$ & $\begin{array}{l}29 \\
(39 / 22)\end{array}$ & $\begin{array}{l}17 \\
(27 / 8)\end{array}$ & $\begin{array}{l}33 \\
(25 / 35)\end{array}$ & 0 & $\begin{array}{l}28 \\
(34 / 24)\end{array}$ \\
\hline Mean age at first adenoma (y) (M/F) & $\begin{array}{l}43.6 \\
(41 / 46)\end{array}$ & $\begin{array}{l}41.4 \\
(38 / 53)\end{array}$ & 0 & $\begin{array}{l}40 \\
(40 / 0)\end{array}$ & $\begin{array}{l}67.5 \\
(65 / 70)\end{array}$ & $\begin{array}{l}51.6 \\
(48 / 56)\end{array}$ & $\begin{array}{l}45 \\
(46 / 42)\end{array}$ & $\begin{array}{l}51.1 \\
(48 / 52)\end{array}$ & 0 & $\begin{array}{l}48 \\
(44 / 52)\end{array}$ \\
\hline
\end{tabular}

1 , gene carrier; 2 , first generation at risk; 3 , second generation at risk; 4 , family member with a negative mutation test; 5 , gene carrier; 6 , first generation at risk; 7 , second generation at risk; 8 , individuals with two close relatives (TCR) with colorectal cancer; 9 , one first degree relative (OCR) with colorectal cancer $<40$ years of age.

(4.5) for tested gene carriers in HNPCC families and also statistically significantly higher for the other two family types (table 3). No difference was demonstrated $(p>0.5)$ between the three family types for adenoma prevalence but a difference in the number of adenomas between family types was observed (fig 1). Individuals with adenomas from TCR families had more adenomas (3.8) than HCC subjects (2.4) and HNPCC families (1.2). The hazard ratio between TCR and HNPCC was 3.3 (CI 2.2-4.6) and between HCC and HNPCC 2.0 (CI 1.3-2.9). The hazard ratio between TCR and HCC was 1.6 (CI 1.1-2.18).

\section{Cancer risk in adenomas}

The prevalence in each risk group varied in relation to the estimated cancer risk in the various risk groups in HNPCC and HCC (table 2). The high prevalence of adenomas in the relatively low risk TCR families was unexpected. To obtain a relative value of cancer risk which could be used for comparisons between different risk groups, prevalence was related to the estimated cancer risk (table 4). The risk values

Table 3 Relative risk (RR) of adenoma in the study group* compared with the reference group $†$

\begin{tabular}{|c|c|c|c|c|c|}
\hline & $\begin{array}{l}\text { No patients } \\
\text { without } \\
\text { adenoma }\end{array}$ & $\begin{array}{l}\text { No patients } \\
\text { with adenoma }\end{array}$ & Tota & & \\
\hline \multicolumn{6}{|c|}{ Reference group lifetime cancer risk $5 \%$} \\
\hline Women & 110 & 12 & 122 & & \\
\hline Men & 191 & 25 & 216 & & \\
\hline Total & 301 & 37 & 338 & & \\
\hline \multicolumn{6}{|c|}{ Whole study group lifetime cancer risk $10-70 \%$} \\
\hline Women & 85 & 29 & 114 & RR2.6 & \\
\hline Men & 60 & 30 & 90 & RR2.8 & \\
\hline Total & 145 & 59 & 204 & RR2.6 & $p<0.001$ \\
\hline \multicolumn{6}{|c|}{ HNPCC gene carriers lifetime risk $70 \%$} \\
\hline Women & 12 & 9 & 21 & RR4.4 & \\
\hline Men & 8 & 10 & 18 & RR4.8 & \\
\hline Total & 20 & 19 & 39 & RR4.5 & $p<0.001$ \\
\hline \multicolumn{6}{|c|}{ HCC lifetime cancer risk 35\% } \\
\hline Women & 23 & 6 & 29 & RR2.1 & \\
\hline Men & 13 & 8 & 21 & RR3.3 & \\
\hline Total & 36 & 14 & 50 & RR2.6 & $p<0.001$ \\
\hline \multicolumn{6}{|c|}{ TCR lifetime cancer risk $15 \%$} \\
\hline Women & 15 & 11 & 26 & RR4.3 & \\
\hline Men & 10 & 2 & 12 & RR 1.4 & \\
\hline Total & 25 & 13 & 38 & RR3.1 & $p<0.001$ \\
\hline
\end{tabular}

* Study group was less than 54 years or age at first adenoma was below 54 years; treference group was less than 54 years of age. HNPCC, hereditary non-polyposis colorectal cancer; HCC, hereditary colorectal cancer; TCR, two close relatives with colorectal cancer. (prevalence/estimated cancer risk) were highest in HNPCC, and lowest in TCR and the normal population. To obtain a relative cancer risk in each adenoma, the risk values were divided by the number of adenomas per individual (from fig 1) (table 4). Mean age of the families was similar (table 2), and the risk of cancer was the same when only subjects less than 54 years of age were compared (data not shown).

\section{Localisation of adenomas and carcinomas}

Adenomas were located throughout the colon and rectum, as depicted in fig 2 . While adenomas were evenly distributed in HNPCC, HCC, and in the general population, TCR adenomas seemed to be mostly proximal (fig 2 ).

To determine if there was a difference in cancer risk depending on location, a comparison was made between adenoma location and carcinoma location in the different family types (fig 2). Localisation of cancers among the total number of family relatives was obtained from investigation of all 111 families in the study. In total, there were 81 HNPCC cancers, 52 HCC cancers, and 51 TCR cancers. To determine the localisation of sporadic cancer in the general population, three published reports ${ }^{20-22}$ were used (fig 2 ). There was a clear difference in percentage of distal outcome between adenomas and carcinomas in families with TCR $(\mathrm{p}<0.001)$ but also in HCC $(p<0.05)$ and the normal population $(p<0.001)$ (fig 2$)$.

\section{Mean age at first observed adenoma}

Mean age at identification of the first adenoma was 43 years in HNPCC, 50 years in HCC, and 52 years in TCR (fig 3). There was a statistically significant difference between age at first adenoma in HNPCC and TCR $(p=0.006)$. The difference

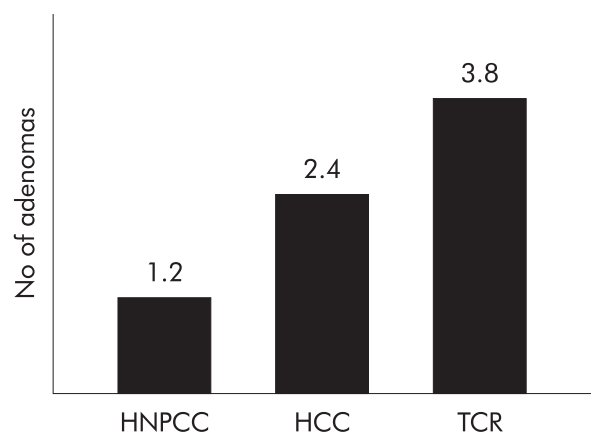

Figure 1 Mean number of adenomas among individuals presenting with adenomas in the three family types (HNPCC, hereditary non-polyposis colorectal cancer; HCC, hereditary colorectal cancer; TCR, two close relatives with colorectal cancer). 
Table 4 Comparison of cancer risks between different syndromes

\begin{tabular}{|c|c|c|c|c|}
\hline & $\begin{array}{l}\text { Cancer risk } \\
\text { (risk/prevalence) }\end{array}$ & $95 \% \mathrm{Cl}$ & $\begin{array}{l}\text { Cancer risk per } \\
\text { adenoma }\end{array}$ & $95 \% \mathrm{Cl}$ \\
\hline HNPCC, subjects at $70 \%$ risk* & $1.43(70 / 49)$ & $1.09-2.06$ & $1.19(1.43 / 1.2)$ & $0.91-1.72$ \\
\hline HNPCC, subjects at $35 \%$ risk* & $1.84(35 / 19)$ & $1.16-4.30$ & $1.53(1.84 / 1.2)$ & $0.97-3.59$ \\
\hline HNPCC, subjects at $17 \%$ risk & - & - & - & - \\
\hline HNPCC, subjects at $5 \%$ risk & $0.38(5 / 13)$ & - & $0.32(0.38 / 1.2)$ & - \\
\hline HCC, subjects at $70 \%$ risk & $1.40(70 / 50)$ & - & $0.58(1.4 / 2.4)$ & - \\
\hline HCC, subjects at $35 \%$ risk* & $1.21(35 / 29)$ & $0.92-1.75$ & $0.50(1.21 / 2.4)$ & $0.38-0.73$ \\
\hline HCC, subjects at $17 \%$ risk & $1.00(17 / 17)$ & $0.55-8.75$ & $0.42(1.00 / 2.4)$ & $0.23-3.65$ \\
\hline TCR, subjects at $15 \%$ risk* & $0.45(15 / 33)$ & $0.39-0.80$ & $0.12(0.45 / 3.8)$ & $0.10-0.21$ \\
\hline Normal population at $5 \%$ risk & $0.45(5 / 11)$ & - & $0.23(0.45 / 2.0)$ & - \\
\hline \multicolumn{5}{|c|}{$\begin{array}{l}\text { * Statistically significant. } \\
95 \% \mathrm{Cl}, 95 \% \text { confidence interval. } \\
\text { HNPCC, hereditary non-polyposis colorectal cancer; HCC, hereditary colorectal cancer; TCR, two close } \\
\text { relatives with colorectal cancer. }\end{array}$} \\
\hline
\end{tabular}

between HNPCC and HCC was as expected $(p=0.02)$ as this was defined by the inclusion criteria.

\section{Sex and age}

Overall, there was a difference $(\mathrm{p}<0.05)$ between the prevalence of adenomas in men (34\%) and women $(24 \%)$ (tables 2,3). Men and women showed a systematic difference in mean age at first adenoma (fig 3). There was no interaction effects; the sex difference was assumed to be constant over family type and the difference between family types was assumed to be constant over sex.

\section{Histopathology}

In total, 152 tubular adenomas, 18 tubulovillous adenomas, two villous adenomas, 18 serrated adenomas, and five unclassified adenomas were removed. The vast majority (88\%) were less than $5 \mathrm{~mm}$. In four of the adenomas estimation of size was not done. Size and degree of dysplasia in adenomas from the second or later colonoscopies were compared. Thirteen adenomas were $>5 \mathrm{~mm}$ in size but only three showed a high degree of dysplasia (table 5). In total, eight subjects had 11 adenomas with high dysplasia, and six of those eight subjects were from HNPCC families (table 6). There was a statistically significant difference between the number of adenomas with high degree dysplasia in the HNPCC compared with the other two family types $\left(\chi^{2}=6.7, p<0.01\right)$.

\section{DISCUSSION}

In the following discussion of the results, we will use the RR of adenomas as an estimate of tumour initiation rate in individuals. When the actual cancer risk in an individual is higher
A

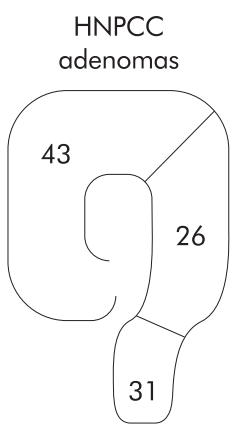

B

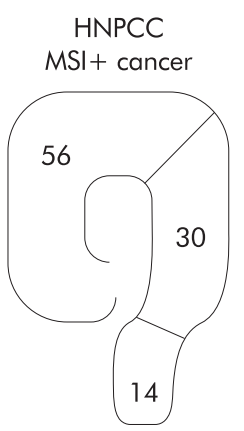

Adenomas
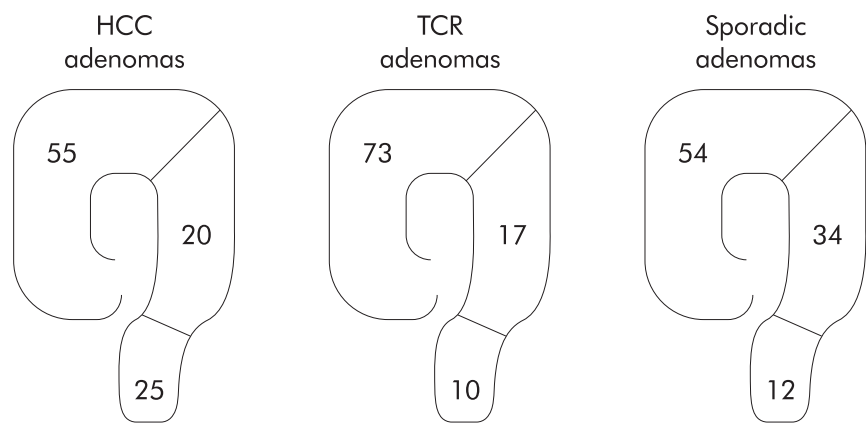

Carcinomas
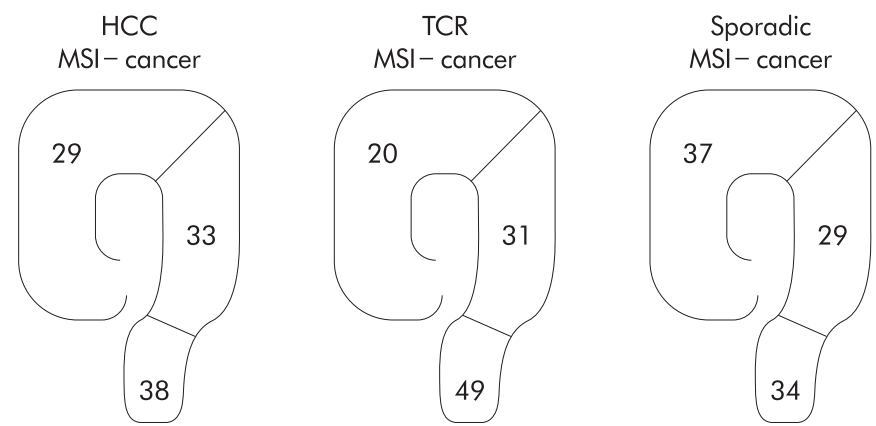

Figure 2 Percentage distribution of adenomas in the three familial types (HNPCC, hereditary non-polyposis colorectal cancer; HCC, hereditary colorectal cancer; TCR, two close relatives with colorectal cancer) and in the reference population (A). Percentage distribution of carcinomas in the same family types and in the general population (B). 


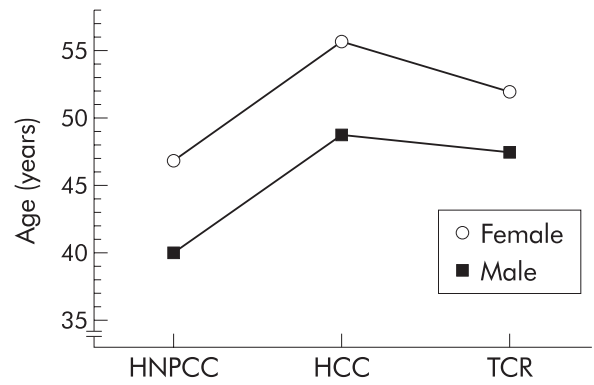

Figure 3 Mean age at onset of adenoma or carcinoma in men and women in the three family types (HNPCC, hereditary non-polyposis colorectal cancer; HCC, hereditary colorectal cancer; TCR, two close relatives with colorectal cancer).

than the increase in initiation rate, this is considered to depend on an increased tumour progression rate in adenomas.

\section{A higher initiation rate in all risk groups}

There is much discussion as to whether the prevalence and frequency of adenomas in individuals with an increased risk of colorectal cancer are higher than in the general population..$^{23-26}$ In this study, gene carriers in HNPCC had an RR of 4.5 compared with the general population of presenting with an adenoma before the age of 54 years. All risk groups combined had an RR of 2.6. The increased risk of adenomas in all groups compared with the general population indicates that in all families there is an increased initiation rate that explains, at least in part, the increased risk of colorectal cancer. The different numbers of adenomas in the family types suggests that the initiation rate is increased most in TCR families and increased least in HNPCC.

Autopsy studies to assess the number of adenomas in the general population are not optimal. However, the autopsy studies chosen for this study were specifically designed to give adenoma values representing the normal population. Furthermore, some authors found autopsies to be more reliable than colonoscopies in detecting adenomas $<10 \mathrm{~mm} .{ }^{27}$ Other studies have shown a missrate of $15-27 \%$ for detecting adenomas $<5$ mm using colonoscopies. ${ }^{28}{ }^{29}$ However, as most of the study objects were included in a surveillance programme, a minute adenoma would show up at the next screening if missed at the previous one, thus giving correct values for prevalence in the study group.

\section{A higher rate of progression in the high risk syndromes} The excess in cancer risk in adenomas in HNPCC and HCC compared with TCR and the general population in this study suggested that apart from increased initiation there is also an increased rate in tumour progression. As the genes for HCC are still unknown, we estimated the penetrance as equal to that of HNPCC. If this is an overestimation, the cancer risk in each adenoma in HCC is also overestimated and could be even lower. In particular, HNPCC subjects have an up to eightfold greater cancer risk in each adenoma compared with TCR subjects and the normal population (table 4). This fits well with an increased mutation rate in tumours because of deficient mismatch repair in this syndrome. The shift from proximal

\begin{tabular}{|c|c|c|c|c|c|c|c|c|}
\hline Family & Patient & Family type & Age (y) & Screen & Size $(\mathrm{mm})$ & Histology & Dysplasia & Location \\
\hline 69 & 77 & HNPCC & 35 & $3 r d$ & 10 & TA & Low & $A$ \\
\hline 5 & 141 & HNPCC & 34 & 6th & 9 & TA & High & D \\
\hline 87 & 248 & $\mathrm{HCC}$ & 68 & 4 th & 10 & TA & Low & DC \\
\hline 87 & 248 & $\mathrm{HCC}$ & 69 & 5th & 10 & TA & Low & $T$ \\
\hline 87 & 247 & $\mathrm{HCC}$ & 44 & $3 r d$ & 7 & VA & Low & $A$ \\
\hline 134 & 90 & $\mathrm{HCC}$ & 46 & 2nd & 6 & TA & Low & $\mathrm{R}$ \\
\hline 24 & 179 & $\mathrm{HCC}$ & 70 & 2nd & 15 & TA & High & D \\
\hline 26 & 204 & $\mathrm{HCC}$ & 75 & $3 r d$ & 10 & TVA & Low & $\mathrm{R}$ \\
\hline 26 & 204 & $\mathrm{HCC}$ & 76 & 4 th & 10 & TVA & Low & $\mathrm{R}$ \\
\hline 26 & 208 & $\mathrm{HCC}$ & 42 & $3 r d$ & 7 & TA & High & $R$ \\
\hline 23 & 30 & $\mathrm{TCR}$ & 40 & 4 th & 6 & TA & Low & A \\
\hline 23 & 30 & TCR & 41 & 5 th & 6 & TA & Low & A \\
\hline 123 & 331 & TCR & 59 & 2nd & 10 & TA & Low & $\mathrm{T}$ \\
\hline \multicolumn{9}{|c|}{$\begin{array}{l}\text { HNPCC, hereditary non-polyposis colorectal cancer; HCC, hereditary colorectal cancer; TCR, two close } \\
\text { relatives with colorectal cancer; TA, tubular adenoma; TVA, tubulovillous adenoma; VA, villous adenoma; } A \text {, } \\
\text { ascending colon; T, transverse colon; D, descending colon; R, rectum. }\end{array}$} \\
\hline
\end{tabular}

\begin{tabular}{|c|c|c|c|c|c|c|c|c|}
\hline Family & Patient & Family type & Age (y) & Screen & Size (mm) & Histology & Dysplasia & Location \\
\hline 3 & 135 & HNPCC & 53 & $3 r d$ & 5 & TVA & High & D \\
\hline 3 & 138 & HNPCC & 58 & 5 th & Unknown & TVA & High & A \\
\hline 3 & 138 & HNPCC & 58 & 6th & 24 & Carcinoma Dukes' A & & A \\
\hline 5 & 139 & HNPCC & 57 & $2 n d$ & Unknown & Adenoma unclassified & High & D \\
\hline 5 & 141 & HNPCC & 34 & 6 th & 9 & TA & High & D \\
\hline 28 & 299 & HNPCC & 40 & 2nd & Unknown & Carcinoma Dukes' A & & R \\
\hline 183 & 326 & HNPCC & 36 & $3 r d$ & Unknown & TA & High & $\mathrm{R}$ \\
\hline 24 & 179 & $\mathrm{HCC}$ & 70 & 2nd & 15 & TA & High & D \\
\hline 24 & 179 & $\mathrm{HCC}$ & 71 & $3 r d$ & Unknown & TA & High & A \\
\hline 100 & 265 & TCR & 69 & $3 \mathrm{rd}$ & 3 & TVA & High & A \\
\hline 100 & 265 & TCR & 69 & $3 r d$ & 1 & TVA & High & $\mathrm{D}$ \\
\hline
\end{tabular}

HNPCC, hereditary non-polyposis colorectal cancer; HCC, hereditary colorectal cancer; TCR, two close relatives with colorectal cancer; TA, tubular adenoma; TVA, tubulovillous adenoma; VA, villous adenoma; $A$, ascending colon; $T$, transverse colon; $D$, descending colon; $R$, rectum. 
Table 7 Modelling of tumour initiation rate and tumour progression rate in the three family types (HNPCC, HCC, TCR) in this study compared with sporadic colorectal cancer where no increased initiation and progression are known, and a fourth syndrome, familial adenomatosis polyposis, where an increased initiation rate is well documented for adenomas

\begin{tabular}{lll}
\hline Family type & $\begin{array}{l}\text { Tumour } \\
\text { initiation }\end{array}$ & Tumor progression \\
\hline Sporadic colorectal cancer & 0 & 0 \\
HNPCC & + & ++++ \\
HCC & ++ & +++ \\
TCR & +++ & + ? (distal adenomas) \\
FAP & ++++ & 0 \\
\hline
\end{tabular}

HNPCC, hereditary non-polyposis colorectal cancer; HCC, hereditary colorectal cancer; TCR, two close relatives with colorectal cancer; FAP, familial adenomatosis polyposis.

0, no increased rate; $+(1-5)$, various degrees of increased rates. This estimation is approximate and only chosen to present the idea of different degrees of increased tumour initiation and tumour promotion rates characterising different families with an increased risk of colorectal cancer because of an inherited predisposition.

adenomas to distal carcinomas among the latter two groups and also in the general population suggests that there is a difference in cancer risk in adenomas depending on the location in the colorectum (fig 2). Thus distal adenomas seem to be associated with a much higher risk of cancer in all patients except HNPCC where the risk of cancer seems equally high in proximal and distal adenomas.

\section{Differences in mean age between syndromes}

Mean age at first observed adenoma was 44 years in HNPCC which is in accordance with previous studies (fig l). The higher penetrance for men in HNPCC found in this study (table 3) confirmed previous reports. ${ }^{30} \mathrm{~A}$ higher penetrance for men was also suggested in HNPCC and HCC in this study, while TCR subjects were not informative in this respect depending on different mean ages among men and women.

In summary, there was a clear overrepresentation of adenomas in all three family types. This seems to justify regular colonoscopy surveillance for prevention in these patients. The data support a proposed model (table 7) with increased rates of both initiation and tumour progression in HNPCC. In HNPCC it appears that there is a rapid transformation from adenoma to carcinoma as there was a higher grade of dysplasia in HNPCC adenomas unrelated to size. HNPCC also displayed the highest risk of cancer in each adenoma, regardless of location (table 4). In HCC families, an increased initiation rate as well as an increased progression rate were also found although the cancer risk in each adenoma was lower in proximal adenomas and the progression from adenoma to carcinoma is likely to be slower than in HNPCC. TCR families seem to have the highest increase in initiation rate as they had the highest number of adenomas. In TCR there seems to be a low cancer risk in proximal adenomas and a relatively higher cancer risk in distal adenomas. The differences between the three family types (HNPCC, HCC, and TCR) with regard to age at onset, prevalence, location, size and degree of dysplasia, and cancer risk of adenomas have been used to revise surveillance protocols in Sweden. The guidelines from the Swedish National Oncogenetic Counsil now recommend the following: in HNPCC, regular colonoscopy every $1-2$ years; in HCC, regular colonoscopy every 3-5 years; and in TCR, colonoscopy (or alternating colonoscopy/sigmoidoscopy) every 3-5 years.

\section{ACKNOWLEDGMENTS}

We are indebted to Marianne Törnblom for excellent management of the patient registry and Jan Kowalski for statistical analysis. The Swedish Cancer Society, the Stockholm County Council, and the Cancer Foundation in Stockholm supported the study.

\section{Authors' affiliations}

G Lindgren, A Lindblom, Department of Clinical Genetics, Karolinska Hospital, S 17176 Stockholm, Sweden

A Liljegren, Department of Clinical Genetics, Karolinska Hospital, S 17 76 Stockholm, Sweden and Department of Clinical Oncology, Danderyds Hospital, S 182 88, Stockholm, Sweden

E Jaramillo, Department of Gastroenterology, Karolinska Hospital, S 17176 Stockholm, Sweden

C Rubio, Department of Oncology and Pathology, Karolinska Hospital, S 17176 Stockholm, Sweden

\section{REFERENCES}

1 Fuchs CS, Giovanni EL, Colditz GA, et al. Family history increases the risk of colorectal cancer. Gastroenterology 1995;109:1015-19.

2 Järvinen HJ, Mecklin J.P, Sistonen P. Screening reduces colorectal cancer rate in families with hereditary nonpolyposis colorectal cancer. Gastroenterology 1995; 108:1405-1 1

3 Järvinen HJ, Aarnio $M$, Mustonen $\mathrm{H}$, et al. Controlled 15-year trial on screening for colorectal cancer in hereditary nonpolyposis colorectal cancer. Gastroenterolgy 2000;1 18:829-34

4 Winawer SJ, Zauber AG, Ho MN, et al. Prevention of colorectal cancer by colonoscopic polypectomy. The National Polyp Study Workgroup. $N$ Engl J Med 1993;329:1977-81.

5 Lynch HT, de la Chapelle A. Genetic susceptibility to non-polyposis colorectal cancer. J Med Genet 1999;36:801-18.

6 Aaltonen LA, Peltomäki P, Leach FS, et al. Clues to the pathogenesis of familial colorectal cancer. Science 1993;260:812-16.

7 Tannergård $\mathbf{P}$, Liu T, Weger A, et al. Tumorigenesis in colorectal tumors from patients with hereditary non-polyposis colorectal cancer. Hum Genet 1997; 101:56-60.

8 Watson P, Lynch HT. Extracolonic cancer in hereditary nonpolyposis colorectal cancer. Cancer 1993;71:677-85.

9 ICG-HNPCC database: http://www.nfdht.nl/database/ mdbchoice.htm.

10 Vasen HFA, Watson P, Mecklin JP, et al. New clinical criteria for hereditary nonpolyposis colorectal cancer (HNPCC, Lynch syndrome) proposed by the International Collaborative group on HNPCC. Gastroenterology 1999;116:1453-6.

11 Lovett E. Family studies in cancer of the colon and rectum. Br J Surg 1976;63:13-18.

12 Aarnio M, Sankila R, Pukkala E, et al. Cancer risk in mutation carriers of DNA-mismatch-repair genes. Int J Cancer 1999;81:214-18.

13 St John DJB, McDermott T, Hopper JL, et al. Cancer risk in relatives of patients with common colorectal cancer. Ann Intern Med 1993; 1 18:785-90.

14 Jass JR, Young PJ, Robinson EM. Predictors of presence, multiplicity, size and dysplasia of colorectal adenomas. A necropsy study in New Zealand. Gut 1992:33:1508-14.

15 Williams AR, Balasooriya BAW, Day DW. Polyps and cancer of the large bowel: a necropsy study in Liverpool. Gut 1982;23:835-42.

16 Clark JC, Collan Y, Eide TJ, et al. Prevalence of polyps in an autopsy series from areas with varying incidence of large-bowel cancer. Int J Cancer 1985;36:179-86.

17 Liu T, Wahlberg S, Burek E, et al. Microsatellite instability as a predictor of a mutation in a DNA mismatch repair gene in familial colorectal cancer. Genes Chrom Cancer 2000;1:17-25.

18 Boland CR, Thibodeau SN, Hamilton SR, et al. A National Cancer Institute Workshop on Microsatellite Instability for Cancer Detection and Familial Predisposition: Development of International Criteria for the Determination of Microsatellite Instability in Colorectal Cancer: Cancer Res 1998:58:5248-57.

19 Wahlberg $\mathrm{S}$, Liu T, Lindblom $\mathrm{P}$, et al. Different mutations screening techniques in the DNA mismatch repair genes hMSH2 and hMLH1. Genet Test 1999;3:259-64

20 Thibodeau SN, Bren G, Schaid D. Microsatellite instability in cancer of the proximal colon. Science 1993;260:816-19.

21 Breivik J, Lothe RA, Meiling Gl, et al. Different genetic pathways to proximal and distal colorectal cancer influenced by sex-related factors. Int J Cancer 1997;74:664-9.

$22 \mathrm{Kim} \mathrm{H}$, Vogelstein B, Hamilton SR. Clinical and pathological characteristics of sporadic colorectal carcinomas with DNA replication errors in microsatellite sequences. Am J Pathol 1994;145: 148-56.

23 Lanspa JS, Lynch HT, Smyrk TC, et al. Colorectal adenomas in the Lynch syndromes. Results of a colonoscopy screening program. Gastroenterology 1990:98:1117-22.

24 Jass JR, Stewart SM. Evolution of hereditary non-polyposis colorectal cancer. Gut 1992;33:783-6. 
25 Ponz de Leon M, Della Casa G, et al. Frequency and type of colorectal tumors in asymptomatic high-risk individuals in families with hereditary nonpolyposis colorectal cancer. Cancer Epidemiol Biom Prev 1998;7:639-41

26 Jass JR, Stewart SM, Stewart J, et al. Hereditary non-polyposis colorectal cancer-morphologies, genes and mutations. Mutat Res 1994;310:125-33

27 Byrd RL, Boggs HW Jr, Slagle GW, et al. Reliability of colonoscopy. Dis Colon Rectum 1989;32:1023-5.
28 Hixon LJ, Fennerty MB, Sampliner RE, et al. Prospective study of the frequency and size distribution of polyps missed by colonoscopy. J Natl Cancer Inst 1990;82:1769-72.

29 Rex DK, Cutler CS, Lemmel GT, et al. Colonoscopic miss rates of adenomas determinded by back-to-back colonoscopies. Gastroenterology 1997:112:24-8.

30 Dunlop MG, Farrington SM, Carothers AD, et al. Cancer risk associated with germline DNA mismatch repair gene mutations. Hum Mol Genet 1997;6:105-10.

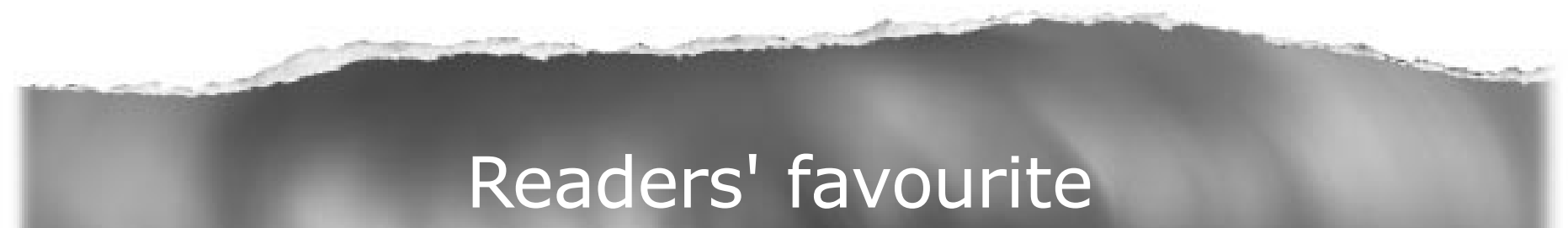

\section{Top 10}

Click on the "Top 10" button on the homepage to see which are the best read articles each month

www.gutjnl.com 


\section{LETTERS}

\section{Intestinal intraepithelial lymphocytes and anti-transglutaminase in a screening algorithm for coeliac disease}

We have noticed the frequent publication of important advances in the serological screening of coeliac disease (CD), such as the interesting and useful technique described by Baldas et al (Gut 2000;47:628-31). Humoral screening of CD is coming closer than ever towards representing an affordable population wide strategy (Gut 2000;47:628-31), largely due to the identification of tissue transglutaminase (tTG) as the main-if not only-autoantigen for antiendomysial antibodies (EMA). ${ }^{1}$ This finding hightlights the possibility of antigen specific testing and, today, determination of anti-tTG is a valid alternative to EMA.

However, we believe that the recent advances in the cellular component of the diagnosis of $\mathrm{CD}$ have been somewhat overlooked. The study of intestinal intraepithelial lymphocytes (IEL) by flow cytometry ${ }^{3}$ has added specificity to mere histological study of the small bowel biopsy. It has been shown that $\mathrm{CD}$ is characterised by an important increase in the TcR- $\gamma \delta^{+}$IEL subset (or $\gamma \delta$ IEL), a decrease in the natural killer (NK)-like subset and, depending on gluten intake, a considerable increase in the TcR- $\alpha \beta^{+}$IEL $(\alpha \beta$ IEL) subset which constitute the majority of IEL. The increase in $\gamma \delta$ IEL (average $4 \%$ in controls $v 25 \%$ in coeliacs, with respect to total IEL) ${ }^{4}$ is not per se diagnostic of $C D$ as it has been observed, although to a lower extent, in food allergy $y^{5}$ and occasionally in other conditions. But CD is the only entity in which $\gamma \delta$ IEL have been described as systematically, permanently, and markedly raised. ${ }^{4}$ The combined study of total, $\gamma \delta$, and NK-like IELs, that could be termed "IEL lymphogram", allows for nearly $94 \%$ specificity and sensitivity in the diagnosis of CD after clinical suspicion. ${ }^{4}$ This technique, complementary to the diagnosis of symptomatic and silent $C D$, shows its real value in latent and potential presentations of the disease, and offers important data for the

If you have a burning desire to respond to a paper published in Gut, why not make use of our "rapid response" option?

Log onto our website, find the paper that interests you, and send your response via email by clicking on the "eletters" option in the box at the top right hand corner.

Providing it isn't libellous or obscene, it will be posted within seven days. You can retrieve it by clicking on "read eletters" on our homepage.

The editors will decide as before whether to also publish it in a future paper issue.

www.gutjnl.com differential diagnosis from other enteropathies. It is noteworthy that the increase in IEL is the earliest detectable alteration in the mucosa, ${ }^{6}$ prior to the increase in lamina propria lymphocytes or architectural changes.

Many recent reviews ${ }^{67}$ have commented on these characteristic serological and cellular findings of $\mathrm{CD}$ but their incorporation into clinical practice is very different. While tTG testing is spreading, IEL phenotypingparticularly by flow cytometry-is still regarded as a research tool rather than a diagnostic test. We consider that the easy procedure of IEL procurement and phenotyping ${ }^{4} 8$ could be routinely performed in many medium sized hospitals, and we propose an initial screening algorithm that takes this "IEL lymphogram" into account (fig 1).

Screening would be based on tTG IgA determination, and seric IgA quantification if anti-tTG was negative. If there was an IgA deficiency, only IgG tests would then be performed. If serum and blood were obtained at the first visit and temporarily cryopreserved, many tests (serum IgA, AGA, EMA, HLA, IgE, other autoantibodies, etc.) could be performed without the patient attending the clinic again.

The establishment of the putative diagnosis would be achieved by mandatory small bowel

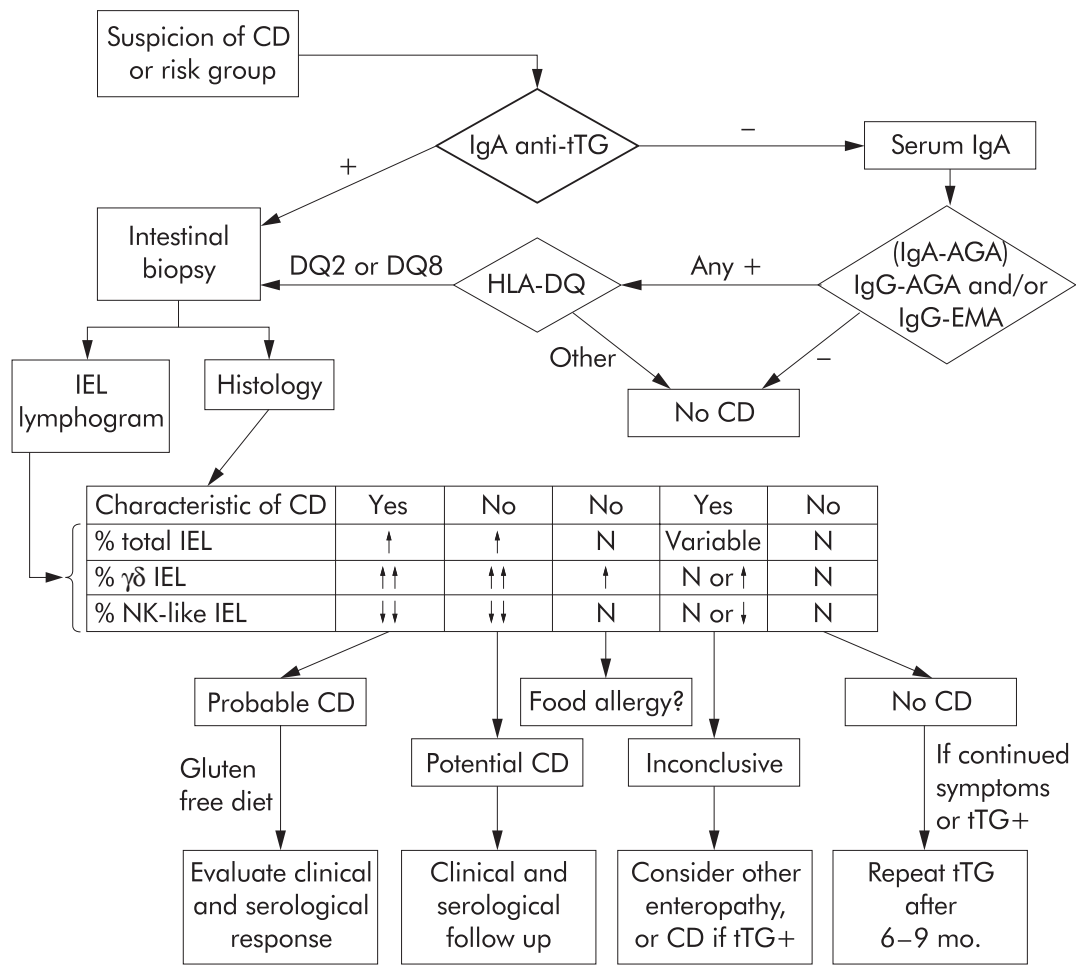

Figure 1 Proposal of an initial diagnostic algorithm for coeliac disease (CD). After screening with anti-transglutaminase ( $\mathrm{tTG}$ ), and taking into account the high negative predictive value of HLA typing, study of mandatory intestinal biopsy would include phenotyping of intraepithelial lymphocytes (IEL). The proportion of "total IEL" is calculated with respect to the cellularity of the epithelium while the proportions of " $\gamma \delta$ IEL" and "natural killer (NK)-like IEL" are relative to the total IEL. The combined analysis of the pathology and the "IEL lymphogram" allows for a correct classification of $>95 \%$ of patients after the first biopsy, reducing the need for subsequent invasive procedures. N, normal values. biopsy. But the IEL lymphogram would allow or serological and clinical evaluation of gluten withdrawal (and challenge) if it fitted into the coeliac pattern and histology showed a typical coeliac enteropathy. If the lymphogram shows high negative predictive value of $95 \%$ agains the existence of $\mathrm{CD}^{4}$ If the interpretation of the immunohistological study is not straightforward, the classical ESPGAN criteria can be followed. ${ }^{9}$ We believe that this algorithm, can be conveniently adapted to the centre, can correctly classify the vast majority of patients, saving time and

F Leon, P Eiras, G Roy Department of Immunology, Hospital Ramón y Cajal, Ctra Colmenar km 9, 28034 Madrid, Spain Department of Paediatric Gastroenterology,

Correspondence to: $\mathrm{F}$ Leon immuno_leon@altavista.com

\section{Acknowledgements}

Our work was financed by the Spanish Fondo de Investigaciones Sanitarias (FIS), grants Nos 00/0196 (G Roy) and 01/9417 (F León). 


\section{References}

1 Dieterich W, Ehnis T, Baver M, et al. Identification of tissue transglutaminase as the autoantigen of coeliac disease. Nat Med 1997:3:797-801.

2 León $\mathbf{F}$, Camarero C, Pena R, et al Anti-transglutaminase IgA ELISA: Clinical potential and drawbacks in celiac disease diagnosis. Scand I Gastroenterol 2001;36:849-53.

3 Eiras P, Roldán E, Camarero C, et al. Flow cytometry description of a novel CD3- CD7 + intraepithelial subset in human duodenal biopsies: potential diagnostic value in coeliac disease. Cytometry 1998;34:95-102.

4 Camarero C, Eiras P, Asensio A, et al. Intraepithelial lymphocytes and coeliac disease: Permanent changes in CD3-/CD7+ and $T$ cell receptor $\gamma \delta$ subsets studied by flow cytometry. Acta Paediatr 2000;89:285-90.

5 Kokkonen J, Holm K, Karttunen TJ, et al. Children with untreated food allergy express a relative increment in the density of duodenal gammadelta + T cells. Scand J Gastroentero 2000;35: $1137-42$

6 Schuppan D. Current concepts of celiac disease pathogenesis. Gastroenterology 2000;1 19:234-42.

7 Ciclitira PJ. AGA technical review on celiac sprue. Gastroenterology 2001 ;20:1526-40.

8 Madrigal L, Lynch S, Feighery C, et al. Flow cytometry analysis of surface major histocompatibility complex class II expression on human epithelial cells prepared from small intestinal biopsies. J Immunol Methods 1993; 158:207-14

9 Report of Working Group of ESPGAN Revised criteria for diagnosis of celiac disease. Arch Dis Child 1990;65:909-11.

\section{The changing scope of colorectal cancer}

We read with great interest the commentary by Boland and Savides (Gut 2001;48:449-50) on our paper "Flexible sigmoidoscopy and the changing distribution of colorectal cancer: implications for screening" (Gut 2001;48:5225). The authors make several important points about the changing pattern of distribution of colorectal cancer and the possible reasons for the changes we observed. Our data showed an increased percentage of colorectal cancers diagnosed proximal to the splenic flexure between 1976-78 and 1990-97. As Boland and Savides point out, this change may be linked to a true increase in the incidence of proximal cancers or to a reduction in the incidence of distal and rectal tumours owing to the widespread use of flexible sigmoidoscopy and the consequent removal of premalignant adenomas.

We recently carried out further analysis of data from the Northern Ireland Colorectal Cancer Registry for the years 1995-97. The results of this analysis are shown in table 1 together with our previously published data for the years 1976-78. All incidences were age standardised per 100000 for each sex using the world standard population.

Table 1 Incidence of proximal, distal, and rectal colorectal cancers in the years indicated. All incidences were age standardised per 100000 for each sex using the world standard population

\begin{tabular}{lllll}
\hline & Year & Proximal colon & Distal colon & Rectum \\
\hline Male & $1976-78$ & 4.7 & 6.1 & 12.5 \\
& $1995-97$ & 9.5 & 8.4 & 12.2 \\
Female & $1976-78$ & 4.7 & 5.8 & 6.0 \\
& $1995-97$ & 8.2 & 6.2 & 6.6 \\
\hline
\end{tabular}

These values show that the age standardised incidence of colonic carcinoma has increased in both sexes over the period studied (proximal more than distal) while the incidence of rectal cancer has remained relatively constant. These data suggest that the changing pattern of distribution of colorectal cancer which we have observed is unlikely to be due to a decreased incidence of distal and rectal cancers. These results may well represent a true increase in proximal colonic cancers, although as Boland and Savides suggest, they could also be explained by a rising incidence in all subsites, with relative sparing of the distal colon and rectum due to either the protective effect of non-steroidal anti-inflammatory drugs or endoscopic polypectomy.

J S White, K Mc Callion, K R Gardiner Department of Surgery, Royal Victoria and Belvoi Park Hospitals, the Queen's University of Belfast,

R M S Mitchell, RG P Watson, J S A Collins

Department of Medicine, Royal Victoria and Belvoir Park Hospitals, the Queen's University of Belfast,

R H Wilson

Department of Oncology, Royal Victoria and Belvoir Park Hospitals, the Queen's University of Belfast, UK

F Kee

Department of Epidemiology and Public Health Royal Victoria and Belvoir Park Hospitals, the Queen's University of Belfast, UK

\section{A Paneth cell surrogate?}

We read with interest the article by Cunliffe $e$ al (Gut 2001;48:176-85) on defensin 5 stored in normal Paneth cells and in metaplastic Paneth cells in inflammatory bowel disease (IBD)

In recent years a great deal of interest has centred around Paneth cells as carriers of innate host defence, effective through their content of antimicrobial peptides and proteins. ${ }^{1}$ In humans, that mechanism seems to be conveyed by a complex system of proteins present in the granules of the Paneth cells: lysozyme, secretory phospholipase A and probably $\alpha$ defensins (that is, cyptidins, so far recorded in mice).

The lysozyme rich granules in Paneth cells appears to be one of the main sources of antimicrobial peptide in the normal small bowe (where Paneth cells are normally present). Although such cells are not found in the normal colorectal mucosa, Paneth cell metaplasia may be present in the colorectal mucosa of some (but not all) patients with longstanding IBD. Demonstration of human neutrophil defensins (HNP 1-3) and lysozyme in epithelial cells of active $\mathrm{IBD}^{2}$ has fuelled interest in

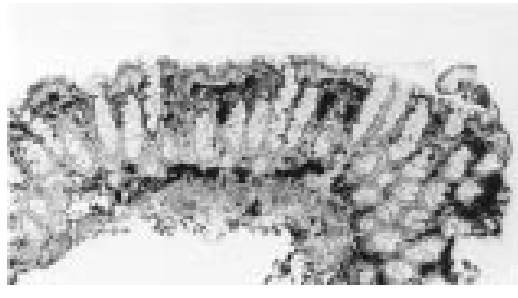

Figure 1 Rectal mucosa in remission in a patient treated in the past for ulcerative colitis. Note the arrangement of lysozyme laden muciphages along the muscularis mucosae, both underneath the superficial epithelium and at the base of the crypts (Lysozyme-Muramidase without counterstain, $25 \times)$.

the molecular events behind defensin mediated intestinal host defence.

Against that background, it may be of interest to point out that another source of cytoplasmic lysozyme has recently been unveiled. ${ }^{3}$ Thirty five years ago, Azzopardi and Evans ${ }^{4}$ found mucin containing macrophages (denominated muciphages) in the colonic mucosa. Those cells were described as normal phagocytes in an otherwise normal mucosa. The mucoprotein present in their cytoplasm stained with a variety of mucus colorants (alcian blue, aldehyde fuchsin, and mucicarmine). Muciphages which were subsequently found to be associated with mucosal abnormalities induced by an inflammatory disruption of the crypts would officiate as scavengers to keep the lamina propria free from the liberated mucus. Until now, muciphages have been considered as a non-specific manifestation of mucosal damage.

While investigating the occurrence of those cells in rectal biopsies from patients with a variety of diseases, we found muciphages either scattered in the lamina propria mucosa or distributed in a more "organised" fashion underneath the superficial epithelium and along the base of the crypts, near the muscularis mucosae.

Immunostain (CD68) confirmed the macrophagic nature of those cells and histochemistry showed the presence of PAS positive mucopolysaccharides. In addition, the cytoplasm of muciphages was strongly positive for lysozyme (Lysozyme-Muramidase stain; Dako A/S, Denmark) (fig l).

At this stage it should be stressed that the mucus contained in the goblet cells of the crypts, in the mucus of mucous producing adenocarcinomas of the rectum, and in the mucus from a ruptured colon diverticulitis were lysozyme negative. Thus the cytoplasm of muciphages contains not only mucins but also the antimicrobial peptide lysozyme.

The presence of lysozyme in muciphages suggests that those particular macrophages are not an accidental happening but expression of a more targeted active biological mechanism of lysozyme dependent mucosal defence.

In some patients with IBD in remission, the topographical disposition of those lysozyme containing cells-between the mucosa and the underlying host (fig 1)-is noteworthy. That arrangement insinuates the possibility of an organised biological hinder (a "defensive barrier"?) against a factor(s) entering the host through the rectal mucosa

The fact that muciphages also contain lysozyme may open new vistas for those previously unattended cells. It is conceivable 
that muciphages may be an important source of antimicrobial peptides in mucosae in protracted remission from earlier inflammatory episodes.

C A Rubio

Gastrointestinal and Liver Pathology, Research Laboratory, Karolinska Institute and Hospital, 171 76 Stockholm, Sweden; Carlos.Rubio@onkpat.ki.se

\section{References}

1 Mahida Y, Rose F, Chang W. Antimicrobial peptides in gastrointestinal tract. Gut 1997;40:161-3.

2 Cunliffe $R$, Rose $F$, James $P$, et al. Expression of antimicrobial neutrophil defensins and lysozyme is induced in epithelial cells of active inflammatory bowel disease (IBD) mucosa Gastroenterology 1999;1 16:G3936.

3 Rubio CA. Rectal muciphages are rich in lysozyme. A novel source of antimicrobia mucosal defense? Scand J Gastroenterol 2002;37:1-2

4 Azzopardi J, Evans D.

Mucoprotein-containing histiocytes (muciphages) in the rectum. J Clin Pathol 1966;19:368-74.

5 Jass J. The large intestine. In: Morson B, ed Alimentary tract, vol 3. Edinburgh: Churcill Livingstone, 1987;313-95.

\section{CORRECTION}

Reference 1 in Lindgren et al (Gut 2002; 50:228-34) should have read Fuchs CS, Giovanni EL, Colditz GA, et al. Family history increases the risk of colorectal cancer. NEJM 1995;109:1015-19. The authors apologise for the error.

\section{NOTICES}

Agostino Trapani International Prize

The Scuola Medica Ospedaliera Napoletana invites applications for the above international prize. A stipend of $€ 7.000$ (seven thousand Euros), generously offered by the Professor Trapani family, is available to subsidise a young investigator submitting an experimental and/or clinical research project in the fields of hepatobiliary and pancreatic disorder. The prize, awarded by an international committee, will be personally presented to the winner during the congress "Progressi in Chirurgia Epato Bilio Pancreatica" which will be held in Napoli on June 20-22, 2002. Travel expenses will be refunded to the winner. Applications, in English, should be sent to the Organising Secretariat (G.P. Pubbliche Relazioni s.r.l., Via San Pasquale a Chiaja 55, 80121 Napoli. Tel: +39081 403837/ 411450; fax: +39 081 404036; email g.p.congress@napoli.com) by 20 May 2002 and should include:
- Curriculum vitae of the applicant

- Research project (max three typewritten pages) including a financial plan to use the stipend

- Covering letter inclusive of formal application

- Address where an acknowledgement of the receipt of the application and any further correspondence should be mailed, including telephone, fax, and email address.

- Letter of nomination of a sponsor of known reputation in the field of hepato pancreatic and biliary surgery.

\section{Broad Medical Research}

Program-Inflammatory Bowel

\section{Disease Grants}

Funds for inflammatory bowel disease (IBD) research are available immediately from the Broad Medical Research Program of The Eli and Edythe L Broad Foundation for innovative projects regarding etiology, therapy, or prevention. Grants totalling approximately US\$100,000 per year are available for basic or clinical projects. Larger erquests may be considered. Initial letter of interest (no submission deadline), simple application, rapid (60 day) peer review, and funding. Criteria for funding includes new ideas or directions, scientific excellence, and originality. Early exploratory projects, scientists not currently working in IBD, and/or interdisciplinary efforts are encouraged. Further information Marciana Poland, Research Administrator, Broad Medical Research Program, 10900 Wilshire Blvd., 12th Floor, Los Angeles, CA 90024-6532, USA. Tel: +1 310954 5091; email: info@broadmedical.org; website: www.broadmedical.org

\section{Falk Symposium No 128: Exogenous Factors in Colonic Carcinogenesis}

This will be held on 2-3 May 2002 in Würzburg, Germany. Further information: Falk Foundation e.V.-congress Division, Leinenweberstr. 5, PO Box 6529, D-79041 Freiburg, Germany. Tel: +49 7611514 0; fax: $\quad+49761 \quad 15 \quad 14$ 359; email symposia@falkfoundation.de

\section{Artificial Oxygen Carriers-A Clinical Future?}

This conference will be held on 9 May 2002 in Edinburgh, UK. Further information: Rosemary Hector, Acting Consensus Conference Co-ordinator, Education and Standards Department, Royal College of Physicians of Edinburgh, 9 Queen Street, Edinburgh EH2 1JQ. Tel: +44 (0)131 225 7324; fax: +44 (0)131220 3939; email: r.hector@rcpe.ac.uk

\section{2th International Workshop of Digestive Endoscopy,} Ultrasonography, and Radiology

This will be held on 30-31 May 2002 in Marseille, France. Further information: Nathalie
Fontant, Atelier Phenix, 41 rue Docteur Morucci, 13006 Marseille, France. Tel: +3304 913750 83; fax: +330491 5715 28; email: nfontant@aphenix.com

\section{Endoscopic Oncology: \\ Gastrointestinal Endoscopy and Cancer Management}

This ASGE Annual Postgraduate Course will be held on 22-23 May 2002 in San Francisco, USA. Further information: American Society for Gastrointestinal Endoscopy. Tel: +1 978 526 8330; fax: + l 978526 7521; email: asge@shore.net

\section{$11^{\text {th }}$ International Symposium} on Hepatic Encephalopathy and Nitrogen Metabolism

This meeting will be held on 30 May to 1 June 2002 in Amsterdam, The Netherlands. Further information: Secretariat, Nicolaes Tulp Institute, Academic Medical Center, PO Box 23123, 1100 DS Amsterdam, The Netherlands. Tel: +3120 566 8585; fax: +31 206963228 ; email: tulpinst@amc.uva.nl.

\section{Gastroenterology and Endotherapy European Workshop: XXth Anniversary}

This course will be held on 17-19 June 2002 in Brussels, Belgium. Further information: Nancy Beauprez, Gastroenterology Department, Erasme Hospital, Route de Lennik 808 B-1070 Brussels, Belgium. Tel: +32 (0)20 555 49 00; fax: +32 (0)20 555 4901; email: beauprez@ulb.ac.be

\section{EASL Monothematic Conference on Vascular Function in Liver Disease}

This conference will take place on 30 June to 2 July 2002 in London, UK. Further information: Professor Jordi Bruix, EASL Liaison Bureau, c/o Kenes International, 17 rue du Cendrier, PO Box 1726, CH-1211 Geneva, Switzerland. Tel: +41 22908 0488; fax: +41 22732 2850; email: info@easl.ch; www.easl.com. Deadline for abstract submission 15 May 2002. Further information: kmoore@ rfc.ucl.ac.uk; tel: +44 (0)2074332876.

\section{5th International Workshop on Pathogenesis and Host Response in Helicobacter Infections}

This will be held on 4-7 July 2002 in Helsingør, Denmark. Further information: Dr Tina Ken Hansen, Department of CardiologyEndocrinology E, Frederiksberg Hospital, Ndr. Fasanvej, DK-2000 Frederiksberg, Denmark. Fax: +45 3545 7708; email: helpatim $a$ biobase.dk 